\section{Privacy and Transplants}

In the past few years, transplant surgeons of all kinds have complained that excitement and sometimes exaggeration in the newspapers have frequently hampered their work. It appears, for example, that the supply of kidneys for transplantation diminishes at least temporarily whenever newspaper readers are being regaled with exciting accounts of how a dying person is rushed across the centre of a city, with a police escort in attendance, and when the relatives of the people concerned, the recipient of a heart transplant or the unfortunate donor are interviewed for publication. What seems to happen is that the relatives of possible donors for kidney operations, now a part of routine medical practice, shrink from giving their consent to the operation for fear they, too, will be harassed by journalists at what is bound to be a distressing time for them. The consequences are serious because the supply of kidneys is not nearly great enough to meet the growing demand, which is why some surgeons have come to resent the interest of the newspapers in transplant operations and, worse still, have sometimes attempted to deny them information. Nobody will pretend that the question is an easy one, which perhaps explains why it has been dealt with somewhat superficially in the Report of the Committee on Privacy under Mr Kenneth Younger which has now been published (Cmnd 5012, HMSO, £2.00) and on which the British government promises to take action in the next parliamentary session.

Transplant operations are genuinely of public interest and there is no cause for denying journalists full information about them. That is the first thing to be acknowledged. Not merely does the public have a right to know what kinds of operations are being undertaken but it is also important that medical people should not be the sole custodians of information about the personal circumstances of donors and recipients. Especially when some forms of transplant operations are necessarily difficult and rare, it would, for example, be a matter of great public interest if they were performed exclusively on wealthy recipients, or if the beneficiaries were in some other sense privileged. Similarly, the public needs to know that the circumstances in which organs are taken for transplantation are seemly, that the donors are selected carefully and that their relatives have been properly consulted. It follows that newspaper journalists should be given full information about all transplant operations in which matters of public interest are, in their view, involved. The question is whether it is then possible to arrange that the information can be dealt with in such a way as not to embarrass the families of those concerned. The fact that one consequence may be a diminution in the supply of kidneys for transplantation is only part of the problemit is in general intolerable that the family of, say, a donor should be exposed to public gaze unless, for some reasc" of their own, they have no objection.

The Younger committee includes a brief discussion of the publicity surrounding two heart transplant operations in Britain in 1969 and 1970. It quotes evidence given by the Press Council that the publication of the identity of donors and recipients was a necessary part of establishing the authenticity of the news as well as an invaluable means of creating a sense of immediacy and of personal involvement among newspaper readers. On balance, the Younger committee takes the view that the Press Council has exaggerated the importance of the freedom of newspapers to publish the names of those involved in transplant operations and it goes on to recommend that the Press Council should draw up a summary of its previous adjudications on subjects like these so as to provide a more convenient framework within which journalists, if they choose, can elect to work. This is not enough. The Press Council, after all, has no power to regulate the way in which newspapers and other journals function.

So would it not be sensible to consider a legal prohibition on the publication of the names of donors and recipients in transplant operations unless the people and relatives concerned had given their consent in writing? Beneath the umbrella of such constraint, it would be much easier than it is at present for hospitals to give full details of transplant operations to journalists, and for the latter to investigate as fully as they chose the circumstances in which particular transplant operations have been carried out. And although it might often seem that a full description of the circumstances might serve to identify the people concerned, these are problems with which the newspapers contend already in other fields--in the reporting of the proceedings of juvenile courts, for example, where the names of those charged with offences must not be published and where it is for newspapers to ensure that they do not unwittingly reveal the identity of the person concerned by too full a description of the circumstances. Although it will be unwelcome to most people that there should be further restrictions on the freedom of the press to publish, the British government should seriously consider a legal restraint on publication of the identity of those involved in transplant operations, coupling it with an obligation on hospitals to provide access to information. And the principle might well be extended to other novel forms of operation, many of them still around the corner-the transplantation of fertilized eggs into the human uterus, for example.

\section{Years Ago}

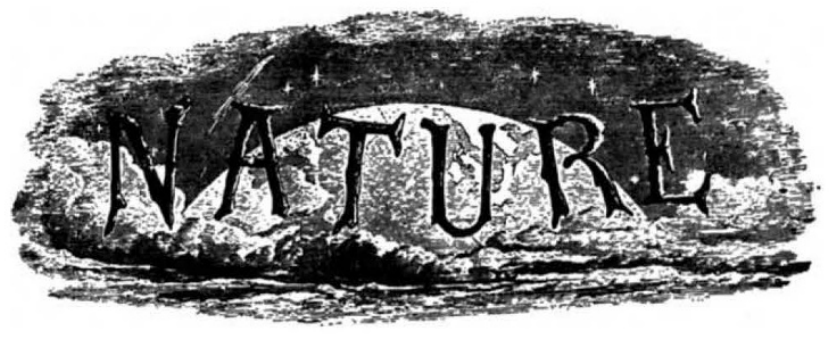

DR. Hayden, in charge of the Geological Survey of the Territories, having completed his preliminary arrangements at Oglen, has separated his forces into two divisions, one of which was to proceed to Fort Hall, with waggons and a suitable outfit, to be changed into a pack train at Fort Hall, and thence to travel up the Snake Valley, under the direction of Mr. Stevenson; the other division, under the doctor's own charge, was to start soon for Fort Ellis, and expected to be at work there by the Ist of July. Among other interesting observations already made by Dr. Hayden's expedition, was the occurrence of invertebrate animal life in great abundance in the Great Salt Lake. This fact is not entirely new, as the existence of dipterous larvx in these waters has already been recorded by Captain Stansbury and others.

From Nature, 6, 330, August 22, 1872. 